\title{
Antiepileptic Drug Treatment in Children with Epilepsy
}

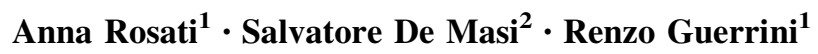

Published online: 23 September 2015

(C) The Author(s) 2015. This article is published with open access at Springerlink.com

\begin{abstract}
Most children with new-onset epilepsy achieve seizure freedom with appropriate antiepileptic drugs (AEDs). However, nearly $20 \%$ will continue to have seizures despite AEDs, as either monotherapy or in combination. Despite the growing market of new molecules over the last 20 years, the proportion of drug-resistant epilepsies has not changed. In this review, we report the evidence of efficacy and safety based on phase III randomized controlled clinical trials (RCTs) of AEDs currently used in the paediatric population. We conducted a literature search using the PubMed database and the Cochrane Database of Systematic Reviews. We also analysed the RCTs of newer AEDs whose efficacy in adolescents and adults might suggest possible use in children. Most of the phase III trials on AEDs in children have major methodological limitations that considerably limit meaningful conclusions about comparative efficacy between old and new molecules. Since the efficacy of new drugs has only been reported versus placebo, the commonly held opinion that new and newer AEDs have a better safety profile than old ones does not appear to be supported by evidence. Despite limited solid evidence, pharmacological management has improved over the years as a consequence of increased awareness of some degree of specificity of treatment in relation to different epilepsy syndromes and attention to adverse events. Future research should be directed taking
\end{abstract}

Renzo Guerrini

r.guerrini@meyer.it

1 Paediatric Neurology Unit, Children's Hospital A. Meyer, University of Firenze, Viale Pieraccini 24, 50139 Florence, Italy

2 Clinical Trial Office, Children's Hospital A. Meyer, Viale Pieraccini 24, 50139 Florence, Italy these factors, as well as the diversity of epilepsy, into consideration.

\section{Key Points}

Most of the phase III trials on antiepileptic drugs (AEDs) conducted to date have major methodological limitations, preventing meaningful conclusions on comparative efficacy between old and new AEDs in children.

The superiority of the new AEDs in terms of efficacy has only been tested versus placebo.

The commonly held opinion that new and newer AEDs have a better safety profile than old ones does not appear to be supported by evidence.

\section{Introduction}

Most children with new-onset epilepsy, especially those with idiopathic generalized epilepsies, achieve seizure freedom with appropriate antiepileptic drugs (AEDs). About $20 \%$ of children with epilepsy will only experience a few seizures in the context of an idiopathic focal syndrome before spontaneous epilepsy remission. However, nearly $20 \%$ of the paediatric epilepsy population will continue to experience seizures despite AEDs, as either monotherapy or in combination [1]. The pharmacological armamentarium for the management of epilepsy in children includes first-generation AEDs [carbamazepine (CBZ), 
clobazam (CLB), clonazepam (CZP), ethosuximide (ETS), phenobarbital (PB), phenytoin (PHT), sulthiame (STM), valproic acid (VPA)] and second-generation AEDs [felbamate (FBM), gabapentin (GPT), lamotrigine (LTG), levetiracetam (LEV), oxcarbazepine (OXC), pregabalin (PGB), tiagabine (TGB), topiramate (TPM), vigabatrin (GVG), zonisamide (ZNS)] [2]. The most recently approved drugs, referred to as third-generation or newer AEDs, include eslicarbazepine acetate (ESL), lacosamide (LCS), perampanel (PER), retigabine (RTG), rufinamide (RUF), and stiripentol (STP).

Most of the second- and third-generation AEDs are licensed as an adjunctive treatment of epilepsy in adults, and are therefore used off-label in paediatric populations on the basis of increasing evidence of their potential efficacy in children, especially in those older than 12 years of age. The highest level of evidence (class I) is based on phase III randomized controlled clinical trials (RTCs) that assess the efficacy of the drug as well as its safety and tolerability.

\section{Literature Search Strategy}

We conducted a MEDLINE literature search using PubMed to identify articles published as of September 2014 with the following limits: (1) randomized controlled trials, guidelines, systematic reviews and meta-analyses; (2) age range between 0 and 18 years; and (3) English language. The literature search strategy identified all articles that included the (MeSH) terms "epilepsy" AND "carbamazepine" OR "clobazam" OR "clonazepam" OR "ethosuximide" OR "phenobarbital" OR "phenytoin" OR "steroids" OR "sulthiame" OR "valproic acid" OR "felbamate" OR "gabapentin" OR "vigabatrin" OR "levetiracetam" OR "lamotrigine" OR "oxcarbazepine" OR "pregabalin" OR "tiagabine" OR "topiramate" OR "zonisamide" OR "eslicarbazepine" OR "lacosamide" OR "perampanel" OR "retigabine" OR "rufinamide" OR "stiripentol" OR "cannabinoids". We also searched the Cochrane Database of Systematic Reviews (topic: child health; section: neurology; sub-sections: epilepsy) for related systematic reviews, including those on mixed populations. The main data extracted included indications, efficacy and adverse events (AEs) in children.

Based on this search, we report the evidence of efficacy based on phase III RCTs of the AEDs currently in use in the paediatric population. Studies including only adults as well as those regarding status epilepticus treatment were excluded. We also analysed the RCTs of newer AEDs whose efficacy in adolescents and adults might suggest their possible use in children. We performed a descriptive analysis without pooling of data, and verified the consistency of the information obtained from the literature review with that reported in the latest National Institute for Health and Care Excellence (NICE) guidelines of 2012 [3]. Information regarding AEs, pharmacokinetic characteristics and drug-drug interactions is more commonly reported in observational studies and is reported in table form (see Tables 1, 2, 3).

\section{Literature Search Results}

The search strategy yielded 469 MEDLINE articles and 28 Cochrane Systematic Reviews. After excluding duplicate publications and including single studies arising from the reviews, 105 studies contributed to this review.

\subsection{First-Generation Antiepileptic Drugs (AEDs)}

\subsubsection{Carbamazepine (CBZ)}

The United States (US) Food and Drug Administration (FDA) approved CBZ in 1968 as first-line and adjunctive therapy for treatment of focal seizures (FS) and generalized tonic-clonic seizures (GTCS). No differences in efficacy were observed between CBZ and PHT as first-line treatment in children with FS and GTCS [4, 5]. CBZ monotherapy was more effective compared to $\mathrm{PB}$ in treating GTCS [6]. A better safety profile in terms of AEs leading to drug withdrawal was reported in children receiving CBZ (4\%) as compared with $\mathrm{PB}$ (6/10 patients enrolled) and PHT (9\%) [4]. A meta-analysis including 1265 participants from five RCTs (two studies including children exclusively, totalling 363 subjects) showed that CBZ and VPA were equally effective for FS and GTCS [7]. In a review including 1384 participants from five RCTs, CBZ monotherapy was as effective as LTG in children and adults with FS or GTCS but had a worse safety profile [8].

A recent Cochrane review, also including studies that were deemed to be of 'poor quality' on mixed populations (734 adults and children) showed CBZ and GVG equivalence in terms of seizure control in children with newly diagnosed focal epilepsy [9-11].

CBZ is considered a first-line drug for FS and has been shown to be effective for GTCS, but it should be avoided in generalized and unclassifiable epilepsies with absences and/or myoclonus as these conditions may be exacerbated by the drug. The last recommendation is based on clinical practice, as confirmed by the Guideline Development Group (GDG) of NICE [3] and supported by case series observations [12]. 
Table 1 Molecular targets and clinical indications of AEDs [110, 117]

\begin{tabular}{|c|c|c|c|c|c|c|}
\hline AED & $\mathrm{Na}^{+}$channels & $\mathrm{Ca}^{+}$channels & GABA & Glutamate & Others & $\begin{array}{l}\text { Clinical efficacy } \\
\text { (type of seizures/syndromes) }\end{array}$ \\
\hline $\mathrm{CBZ}$ & + & & & & & FS, GTCS \\
\hline CLB & & & $\mathrm{GABA}_{\mathrm{A}}$ receptors & & & Broad spectrum \\
\hline $\mathrm{CZP}$ & & & $\mathrm{GABA}_{\mathrm{A}}$ receptors & & & Broad spectrum \\
\hline ETS & + & & & & & Absence \\
\hline PB & & + & $\mathrm{GABA}_{\mathrm{A}}$ receptors & & & FS, GTCS, myoclonic \\
\hline PHT & + & & & & & FS, GTCS \\
\hline VPA & & & $\mathrm{GABA}_{\mathrm{A}}$ receptors & NMDA receptors & & Broad spectrum \\
\hline FBM & + & & $\mathrm{GABA}_{\mathrm{A}}$ receptors & NMDA receptors & & $\begin{array}{l}\text { Atonic, tonic, atypical absence } \\
\text { in LGS }\end{array}$ \\
\hline GPT & & + & $\mathrm{GABA}_{\mathrm{B}}$ receptors & & & FS \\
\hline GVG & & & GABA transaminase & & & FS, infantile spasms \\
\hline LEV & & & & & SV2A & FS, GTCS, myoclonic \\
\hline LTG & + & + & & & & $\begin{array}{l}\text { FS, GTCS, absence, infantile } \\
\text { spasms }\end{array}$ \\
\hline $\mathrm{OXC}$ & + & & & & & FS, GTCS \\
\hline PGB & & + & & & & FS \\
\hline TGB & & & GABA transporters & & & FS \\
\hline TPM & + & & $\mathrm{GABA}_{\mathrm{A}}$ receptors & & Carbonic anhydrase & $\begin{array}{l}\text { FS, GTCS, myoclonic, } \\
\text { infantile spasms }\end{array}$ \\
\hline ZNS & + & + & & & Carbonic anhydrase & FS \\
\hline ESL & + & & & & & FS \\
\hline LCS & + & & & & & FS \\
\hline PER & & & & AMPA receptors & & FS \\
\hline RTG & & & & & KCNQ channels & FS \\
\hline RUF & + & & & & & $\mathrm{FS}$, atonic, tonic in LGS \\
\hline STM & & & & & Carbonic anhydrase & FS \\
\hline STP & & & $\mathrm{GABA}_{\mathrm{A}}$ receptors & & & SMEI or Dravet syndrome \\
\hline
\end{tabular}

+ Indicates the mechanism of action of the drug

$A E D$ antiepileptic drug, $A M P A \alpha$-amino-3-hydroxy-5-methyl-4-isoxazolepropionic acid, $C B Z$ carbamazepine, $C L B$ clobazam, $C Z P$ clonazepam, $E S L$ eslicarbazepine acetate, ETS ethosuximide, FBM felbamate, FS focal seizures, GABA $\gamma$-amonobutyric acid, GPT gabapentin, GTCS generalized tonic-clonic seizures, $G V G$ vigabatrin, $K C N Q$ potassium voltage-gated channel, $L C S$ lacosamide, $L E V$ levetiracetam, $L G S$ LennoxGastaut syndrome, $L T G$ lamotrigine, $N M D A N$-methyl-D-aspartate, $O X C$ oxcarbazepine, $P B$ phenobarbital, $P E R$ perampanel, $P G B$ pregabalin, $P H T$ phenytoin, $R T G$ retigabine, $R U F$ rufinamide, SMEI severe myoclonic epilepsy of infancy, $S T M$ sulthiame, STP stiripentol, $S V 2 A$ synaptic vesicle protein, $T G B$ tiagabine, $T P M$ topiramate, $V P A$ valproic acid, $Z N S$ zonisamide

\subsubsection{Clobazam (CLB)}

CLB is currently approved for use as an AED in more than 100 countries. CLB was approved in the USA in 2010 for adjunctive treatment of Lennox-Gastaut syndrome (LGS) in patients aged 2 years or older.

According to a multicentre Canadian study including 235 patients randomized to CLB versus CBZ and PHT, CLB monotherapy has an efficacy equivalent to that of CBZ and PHT for children with FS or GTCS [13]. Length of retention of the initial medication during the first 12 months after randomization, considered to reflect both efficacy and safety information, was the primary endpoint adopted in the study and was $23 \%$ for the CLB group, $25 \%$ for the CBZ group, and $11 \%$ for the PHT group. AEs were behavioural in the CLB group and most often dermatological in the PHT and CBZ groups, while tolerance developed in $7.5 \%$ of patients receiving CLB versus 4.2 and $6.7 \%$ of those receiving CBZ and PHT, respectively.

Efficacy of adjunctive CLB in refractory focal epilepsy was assessed only in a small double-blind, randomized, placebo-controlled, cross-over study hampered by several methodological limitations (unclear allocation concealment, 
Table 2 AED daily dosage and PK interactions with other AEDs [110, 113-115]

\begin{tabular}{|c|c|c|}
\hline AED & Dosage (oral) (mg/kg/day) & AEDs interactions \\
\hline CBZ & $10-20$ & PB, VPA, LTG, ESL, LCS, PER, STP, CZP \\
\hline CLB & 0.5-1 (maximum $30 \mathrm{mg} /$ day) & FBM, GVG, PGB, STP \\
\hline $\mathrm{CZP}$ & $3-6$ & CBZ, PB, PHT, VPA \\
\hline ETS & $20-30$ & VPA \\
\hline PB & $3-5<5$ years; $2-3>5$ years & CBZ, PHT, VPA, ESL, LCS, PER, RUF, STP, CZP \\
\hline PHT & $8-10<3$ years $; 4-7>3$ years & $\begin{array}{l}\text { PB, VPA, GVG, OXC, TPM, ESL, LCS, PER, RUF, STP, } \\
\text { CZP }\end{array}$ \\
\hline VPA & $15-40$ & CBZ, ETS, PB, PHT, LTG, TPM, CZP \\
\hline FBM & $15-45$ & CLB \\
\hline GPT & $25-35$ & \\
\hline GVG & $20-80 ; 100-150$ for infantile spasms & CLB, PHT, RUF \\
\hline LEV & $20-40$ & \\
\hline LTG & $\begin{array}{l}\text { 5-15 (add-on enzyme inducers); } 1-3 \text { (add-on VPA); } \\
1-5 \text { (add-on VPA + inducers) }\end{array}$ & CBZ, VPA, OXC, RUF, RTG \\
\hline $\mathrm{OXC}$ & $30-45$ & PHT, LTG, PER \\
\hline PGB & 600 mg/day (adults) & CLB, TGB \\
\hline TGB & $0.5-2$ & PGB \\
\hline TPM & $4-6$ & PHT, VPA, ZNS, ESL \\
\hline ZNS & $4-12$ & TPM \\
\hline ESL & 800-1200 mg/day (adults) & CBZ, PB, PHT, TPM \\
\hline LCS & 200-400 mg/day (adults) & CBZ, PB, PHT \\
\hline PER & $8-12 \mathrm{mg} /$ day (>12 years) & CBZ, PHT, PB, OXC \\
\hline RTG & 1200 mg/day (adults) & LTG \\
\hline RUF & $30-40$ & PB, PHT, GVG, LTG \\
\hline STM & 5 & CLB \\
\hline STP & 50 & CBZ, CLB, PB, PHT \\
\hline
\end{tabular}

$A E D$ antiepileptic drug, $C B Z$ carbamazepine, $C L B$ clobazam, $C Z P$ clonazepam, $E S L$ eslicarbazepine acetate, $E T S$ ethosuximide, $F B M$ felbamate, GPT gabapentin, GVG vigabatrin, $L C S$ lacosamide, $L E V$ levetiracetam, $L T G$ lamotrigine, $O X C$ oxcarbazepine, $P B$ phenobarbital, $P E R$ perampanel, $P G B$ pregabalin, $P H T$ phenytoin, $R T G$ retigabine, $R U F$ rufinamide, $S T M$ sulthiame, $S T P$ stiripentol, $T G B$ tiagabine, $T P M$ topiramate, $V P A$ valproic acid, ZNS zonisamide

generation of random sequence and method of blinding) [14]. A total of 21 individuals (13 with GTCS and eight with FS), aged 2-19 years, were enrolled for a treatment period of 3 months followed by a 1-month washout period [14]. The authors reported a $50 \%$ or greater reduction in seizure frequency compared with baseline in 11 of 21 subjects $(52.4 \%)$ during the CLB period as compared with none during the placebo period. Best responder analysis showed only subjects with FS were significant responders $(P<0.05)$. Larger RCTs conducted over a longer period are required to confirm CLB efficacy in FS.

A recent Cochrane review including children and adults comparing the efficacy of several adjunctive therapies (CLB, FBM, RUF, TPM and LTG) for LGS indicates that high-dosage CLB (1.0 mg/kg/day) was the most effective treatment when using a Cohen's transformation of the effect size $[15,16]$. An open-label extension study (OV-
1014) including 267 individuals from two different trials (OV-1002 and OV-1012) seems to confirm the long-term effectiveness of adjunctive CLB in reducing atonic seizures and total seizure frequency in LGS. This conclusion should be weighed cautiously as the rate of loss to follow-up was $30 \%$ and both children and adults were enrolled [17-19].

CLB is not recommended as a first-line treatment because of both a lack of evidence of superiority compared with $\mathrm{CBZ}$ and PHT and concerns about tolerance [20]. High doses of CLB have only been used as add-on in LGS [16].

\subsubsection{Clonazepam (CZP)}

Benzodiazepines, like CZP, were initially approved in USA in the 1970s as second- and third-line therapy for FS and GTCS. Efficacy of add-on CZP compared with placebo was suggested by a study enrolling ten patients with simple 
Table 3 Most commonly reported AEs of AEDs

\begin{tabular}{|c|c|c|}
\hline AED & Common AEs & Severe AEs \\
\hline CBZ & Ataxia, diplopia, rash [117] & $\begin{array}{l}\text { Aplastic anaemia, agranulocytosis, liver toxicity, SJS/TEN, } \\
\text { pancreatitis, SLE [117] }\end{array}$ \\
\hline CLB & Sedation [117] & No \\
\hline $\mathrm{CZP}$ & Sedation [117] & No \\
\hline ETS & Gastric discomfort, hiccups, rash, blurred vision, headache [117] & $\begin{array}{l}\text { Aplastic anaemia, agranulocytosis, SJS/TEN, liver toxicity, } \\
\text { SLE [117] }\end{array}$ \\
\hline $\mathrm{PB}$ & Behavioural problems, drowsiness, rash, cognitive impairment [117] & Agranulocytosis, SJS/TEN, liver toxicity, SLE [117] \\
\hline PHT & $\begin{array}{l}\text { Ataxia, diplopia, nystagmus, acne, gum hypertrophy, hirsutism, } \\
\text { cognitive and sedative affects, peripheral neuropathy [117] }\end{array}$ & $\begin{array}{l}\text { Megaloblastic anaemia, lymphoma, agranulocytosis, SJS/ } \\
\text { TEN, liver toxicity, SLE, encephalopathy, choreoathetosis } \\
\text { [117] }\end{array}$ \\
\hline VPA & $\begin{array}{l}\text { Nausea, epigastric pain, tremor, alopecia, weight gain, } \\
\text { hyperammonaemia [117] }\end{array}$ & $\begin{array}{l}\text { SJS/TEN, liver toxicity, SLE, pancreatitis, encephalopathy } \\
\text { [117] }\end{array}$ \\
\hline FBM & $\begin{array}{l}\text { Insomnia, somnolence, behavioural problems, movement disorders, } \\
\text { vomiting, anorexia, urolithiasis }[44,116]\end{array}$ & $\begin{array}{l}\text { Aplastic anaemia, agranulocytosis, SJS/TEN, liver toxicity, } \\
\text { pancreatitis, SLE [116] }\end{array}$ \\
\hline GPT & $\begin{array}{l}\text { Asthenia, somnolence, depression, behavioural problems, ataxia, } \\
\text { diplopia, rash, urinary incontinence }[45,47,116]\end{array}$ & SJS/TEN, liver toxicity, behavioural problems [116] \\
\hline GVG & $\begin{array}{l}\text { Sedation, behavioural problems, hallucinations, blurred vision, } \\
\text { nausea, anorexia, weight gain, MRI abnormalities }[9,10,116]\end{array}$ & $\begin{array}{l}\text { Liver toxicity, pancreatitis, psychosis, visual field defects, } \\
\text { encephalopathy [116] }\end{array}$ \\
\hline LEV & $\begin{array}{l}\text { Asthenia, somnolence, behavioural problems, hallucinations, } \\
\text { headache, vomiting, infections }[55-57,116,118]\end{array}$ & Psychotic events, liver toxicity, pancreatitis $[55,116]$ \\
\hline LTG & $\begin{array}{l}\text { Behavioural problems, ataxia, tremor, dizziness, diplopia, dyskinesia, } \\
\text { tics, nausea, rash, infections, fever }[51,52,116]\end{array}$ & $\begin{array}{l}\text { Aplastic anaemia, SJS/TEN, liver toxicity, pancreatitis. } \\
\text { Lyell's syndrome [116] }\end{array}$ \\
\hline $\mathrm{OXC}$ & $\begin{array}{l}\text { Asthenia, somnolence, behavioural problems, ataxia, dizziness, } \\
\text { diplopia, headache, abdominal pain, nausea, vomiting, rash, }\end{array}$ & SJS/TEN, liver toxicity [116] \\
\hline
\end{tabular}

PGB Somnolence, behavioural problems, dizziness, weight gain, ataxia

TGB Asthenia, somnolence, behavioural problems, hallucinations, dizziness [70, 71]

TPM Asthenia, somnolence, aphasia, dysarthria, depression, behavioural problems, hallucinations, ataxia, dizziness, paresthesia, headache, diarrhoea, nausea, anorexia, hypohidrosis, urolithiasis, infections, fever [73, 75-77, 116]

ZNS Asthenia, somnolence, behavioural problems, headache, constipation, No diarrhoea, abdominal pain, nausea, vomiting, anorexia, rash, urolithiasis, infections, fever [27-86, 116]

ESL Dizziness, nausea, diplopia ${ }^{a}$ [87]

No

LCS Insomnia, somnolence, depression, suicidal ideation, behavioural problems, blurred vision, tics, nausea, haematological abnormalities [89, 90, 116]

PER Dizziness, nausea, somnolence, fatigue, irritability, headache ${ }^{\mathrm{a}}$ [91]

RTG Dizziness, somnolence, headache, fatigue, confusional state, dysarthria, ataxia, blurred vision, tremor, nausea, urinary tract infections ${ }^{\mathrm{a}}$ [95]

RUF Ashenia, somnolence, dizziness, diplopia, headache, nausea, vomiting, anorexia, rash [97, 100, 116]

STM Somnolence, vomiting, restlessness, anorexia [39-42]

SJS/TEN, non convulsive status epilepticus [116]

SJS/TEN, liver toxicity, pancreatitis [116]

STP Insomnia, somnolence, aphasia, dysarthria, behavioural problems, ataxia, tremor, diplopia, headache, abdominal pain, nausea, vomiting, anorexia, weight gain, rash [103, 106, 116]

$A E$ adverse event, $A E D$ antiepileptic drug, $C B Z$ carbamazepine, $C L B$ clobazam, $C Z P$ clonazepam, ESL eslicarbazepine acetate, ETS ethosuximide, FBM felbamate, $G P T$ gabapentin, $G V G$ vigabatrin, $L C S$ lacosamide, $L E V$ levetiracetam, $L T G$ lamotrigine, $O X C$ oxcarbazepine, $P B$ phenobarbital, $P E R$ perampanel, $P G B$ pregabalin, $P H T$ phenytoin, RTG retigabine, RUF rufinamide, SJS Stevens-Johnson syndrome, SLE systemic lupus erythematosus, $S T M$ sulthiame, $S T P$ stiripentol, $T E N$ toxic epidermal necrolysis, $T G B$ tiagabine, $T P M$ topiramate, $V P A$ valproic acid, ZNS zonisamide

${ }^{a}$ Adult studies only 
absences and ten patients with myoclonic atonic seizures. CZP was more effective than placebo, and more AEs were reported in patients treated with high dosage [21].

A small, double-blind, cross-over RCT enrolling 11 subjects aged 3-18 years with focal and generalized epilepsy, preceded by a pilot study, showed a single low dose of intramuscular CZP to be effective in reducing epileptiform electroencephalogram (EEG) abnormalities as compared with placebo $(P=0.0015)$ [22]. Seven out of the 11 subjects also had a significant reduction in seizure frequency as compared with those under placebo.

According to the NICE guidelines, the use of CZP in patients with absences and myoclonic seizures is recommended when first-line drugs are ineffective or not tolerated [3]. Tolerance may develop over time, making CZP unsuitable for use in long-term epilepsy management [20].

\subsubsection{Corticosteroids (Hydrocortisone, Prednisolone) and Adrenocorticotropic Hormone (ACTH)}

In the USA and Europe, these molecules are used as AEDs in special situations only. In a recent Cochrane review on the treatment of infantile spasms or West syndrome [23], adrenocorticotropic hormone (ACTH) was more effective than low-dose prednisone in achieving both spasm control (odds ratio-OR 4.19, $95 \%$ confidence interval-CI 1.42-12.34) [24, 25] and hypsarrhythmia reduction (OR 10.10, $95 \%$ CI 2.36-43.19) [25]. No differences were found between high and low doses of ACTH in terms of cessation of spasms (OR 1.06, $95 \% \mathrm{CI}$ 0.44-2.56), relapse rates (OR $0.79,95 \%$ CI $0.33-1.88$ ) and resolution of hypsarrhythmia (OR 1.94, $95 \%$ CI $0.60-6.20)[24,26]$.

ACTH was as effective as high-dose prednisolone in reducing spasms (OR 1.35, $95 \%$ CI 0.41-4.38) and more effective (although not significantly so) in reducing EEG abnormalities (OR 3.04, 95 \% CI 0.52-17.66) [26]. ACTH is more effective than GVG, with the sole exception of patients with tuberous sclerosis [27], in controlling spasms (OR 0.42, $95 \%$ CI 0.21-0.80) and EEG resolution (OR $0.38,95 \%$ CI 0.15-0.99) [23, 28-30]. Low-dose ACTH or prednisolone should be considered for treatment of cryptogenic infantile spasms and as second-line therapy in tuberous sclerosis patients [23].

\subsubsection{Ethosuximide (ETS)}

ETS was approved in the USA in 1970 as first-line and adjunctive therapy for treatment of generalized absence seizures. A review by Posner et al. [31], which only included four studies, showed uncertain results when comparing ETS, VPA or LTG in the treatment of absence seizures [32-35]. In a recent double-blind, randomized, controlled trial comparing the efficacy, tolerability, and neuropsychological effects of ETS, VPA and LTG in 453 children with newly diagnosed childhood absence epilepsy, ETS was similar to VPA and both were more effective than LTG in terms of freedomfrom-failure rates after 16 weeks of therapy (OR 1.26, $95 \%$ CI 0.80-1.98) [36]. However, ETS is considered to be the agent of choice for childhood absence epilepsy without GTCS because of a lower risk of attention dysfunction compared with VPA (33 vs. $49 \%$ ) [36].

\subsubsection{Phenobarbital (PB)}

PB is approved in the USA and Europe as adjunctive and first-line therapy for treatment of FS and generalized seizures, including myoclonus but not absences. PB showed similar efficacy when compared with CBZ and PHT in treating FS and was also as effective as PHT for managing GTCS in children [6,37]. In a randomized, comparative, monotherapy trial of PB, PHT, CBZ or VPA for newly diagnosed childhood epilepsy, AEs leading to drug withdrawal were observed more frequently in patients receiving PB compared with those in the CBZ (4\%), PHT (9\%) and VPA (4\%) groups [4]. Allocation to the PB group was interrupted because of the high rate of unacceptable AEs (6/10 children enrolled) [4].

The use of PB as a first-line drug is limited by the frequent, especially cognitive and behavioural, AEs.

\subsubsection{Phenytoin (PHT)}

PHT was approved in the USA in 1953 as first-line and adjunctive therapy for treatment of FS and generalized seizures, except myoclonic and absence seizures. A Cochrane review assessed 11 RCTs including mixed populations with FS or GTCS and the efficacy of PHT or VPA monotherapy in terms of reduction of seizure frequency at 6 and 12 months, the time of first seizure appearance after treatment initiation, and the time of drug discontinuation [38]. No differences were observed for either outcome, even when the analysis was disaggregated by type of seizure subgroup or limited to an age at onset of $>30$ years. An analysis concerning these two drugs limited to paediatric populations was not specifically included in the review, although the only study providing quantitative data for children confirmed a comparable efficacy and safety profile [4]. The relative risk (RR) of time to first seizure was 0.87 (95\% CI 0.63-1.19) for PHT and 1.10 (95\% CI 0.77-1.47) for VPA when compared with the average odds for the four drugs combined. Similar results were observed for time to 1-year remission (RR 1.29, $95 \%$ CI $0.93-1.78$, for PHT and RR 1.13, 95 \% CI 0.80-1.59, for VPA). 
AEs leading to drug withdrawal were more frequent in the PHT group (9\%) than in the VPA group (4\%), although these results were obtained in a small number of patients [4]. PHT and CBZ showed similar efficacy in children and adult populations in controlling both FS and GTCS in terms of time to withdrawal (OR 0.97, $95 \% \mathrm{CI}$ 0.74-1.28) [5].

PHT is an effective first-line drug in treating FS and GTCS, but its use is limited by the frequent AEs [4]. According to GDG opinion, the NICE guidelines recommend avoiding PHT in epilepsies with absences and/or myoclonus as these seizure types may be exacerbated by the drug [3].

\subsubsection{Sulthiame (STM)}

STM is not licensed by the FDA and has not been evaluated by the European Medicines Agency (EMA). Two recent Cochrane reviews considered efficacy studies of adjunctive STM in treating infantile spasms [23, 39]. Hancock et al. [23] analysed the report by Debus and Kurlemann [40], updated with personal communications from the authors. The study included 51 children aged 3-18 months, randomized to treatment or placebo. Both arms received add-on pyridoxine. The cessation of spasms and EEG resolution was more frequent in the STM group (OR 5.13, $95 \%$ CI 1.22-21.47) [23]. In the second review [39], only data included in the original study by Debus and Kurlemann [40] were considered. In this study, 37 children aged 3-15 months were enrolled and assessed for complete cessation of seizure activity during a 9-day period (6/20 in the STM group vs. 0/17 in the placebo group, $P=0.02)$, for all AEs $(P=0.63)$ and for somnolence $(P=0.2)$. Rating et al. [41] found a better efficacy of STM compared with placebo in terms of seizure freedom at 3 (RR 2.26, $95 \%$ CI 1.48-3.44) and 6 months (RR 2.63, $95 \%$ CI 1.43-4.86) and time to first seizure after randomization (hazard ratio-HR 7.80, $95 \%$ CI 2.66-22.87) in 66 patients with benign epilepsy with centro-temporal spikes (BECTS). In this study, STM was as well tolerated as placebo, with a similar rate of withdrawal due to AEs. The efficacy and safety of STM as monotherapy in epilepsy were evaluated in a recent Cochrane review [42] that included three studies comparing STM with PHT or placebo in BECTS and a mixed population with GTCS. No data were reported for the efficacy endpoints, and the assessment of AEs was incomplete. Patients receiving STM were significantly less likely to develop gingival hyperplasia than those receiving $\mathrm{PHT}$ in the GTCS study (RR 0.03, $95 \% \mathrm{CI}$ 0.00-0.58) [42]. The drug may be considered in the treatment of BECTS as monotherapy [41]. However, in our opinion, treatment is seldom necessary in BECTS.

\subsubsection{Valproic Acid (VPA)}

VPA was first approved as first-line and adjunctive therapy for the treatment of generalized epilepsies in 1967 by EMA and in 1978 by the FDA, respectively.

A meta-analysis and a Cochrane review analysed comparative trials including both children and adults, and showed that VPA was as effective as CBZ and PHT in new onset focal epilepsy [7, 38]. These results were confirmed when only paediatric studies were considered (no formal subgroup analysis was performed by the reviewers). A better efficacy for VPA and ETS compared with LTG in treating absence seizures in children and adolescents emerged from a recent RCT [36]. VPA showed a favourable tolerability profile with minimal AEs.

VPA has a broad-spectrum efficacy and is a first-choice medication in childhood focal and generalized epilepsy. VPA is preferred to ETS in subjects with syndromes with a higher risk of GTCS, such as juvenile absence epilepsy [36]. Nonetheless, benefits should always be weighed against the risk of AEs, especially liver toxicity in young children with an aetiology that is still undiagnosed (Table 3).

\subsection{Second-Generation AEDs}

\subsubsection{Felbamate (FBM)}

FBM was initially approved by the FDA in 1993 as add-on treatment of LGS and focal and secondary generalized seizures in patients refractory to other agents. The efficacy of FBM as an add-on in the treatment of refractory focal epilepsy was assessed in adults only, with no differences being found when compared with placebo [43]. Its efficacy and tolerability versus placebo when used as an add-on treatment in LGS were reported in a multicentre study enrolling children and adults (mean age 12 and 14 years in the FBM and placebo groups, respectively) [44]. There were no significant differences in the frequency of seizures recorded during 4-h video monitoring between the baseline phase, treatment phase $(P=0.32)$ and maintenance period $(P=0.19)$. A significant reduction in the frequency of atonic seizures was reported during the treatment $(P=0.01)$ and maintenance periods $(P=0.002)$. The global evaluation score improvement was significantly higher in the FBM group compared with the placebo group $(P<0.001)$. A significant reduction $(P=0.017)$ in the number of tonic-clonic seizures was also reported in the FBM group, but only during the maintenance period (secondary endpoint).

Because of limited evidence of efficacy and the high rate of AEs (Table 3), the use of FBM is controversial and, as reported in NICE guidelines, should be limited to third- 
level centres in the add-on therapy of primary and secondary GTCS [3].

\subsubsection{Gabapentin (GPT)}

In 1993, GPT was approved by the FDA as adjunctive therapy in the treatment of FS, with or without secondary generalization, in adults and paediatric patients 3 years and older. The efficacy of GPT as add-on therapy for refractory FS was evaluated in a double-blind, placebo-controlled trial enrolling 247 children aged 3-12 years [45]. Responder rates (50\% reduction of seizures) favoured GPT, but the difference between treatment groups did not reach statistical significance (RR 1.28, $95 \%$ CI 0.76-2.16). In a recent Cochrane review [46], GPT showed a better efficacy profile (50\% reduction in seizure frequency) compared with placebo when the analysis was conducted in all studies including children and adult populations (RR $1.89,95 \%$ CI 1.40-2.55) [46]. A subgroup analysis by age was not performed.

The efficacy of GPT monotherapy in the treatment of absence seizures was evaluated in an RCT enrolling 33 children aged 4-12 years [47]. No significant differences in seizure frequency in the 2-week double-blind phase were observed when comparing GPT monotherapy at $9.7-19.1 \mathrm{mg} / \mathrm{kg} /$ day to placebo [47].

There is no evidence supporting the efficacy of GPT as add-on in refractory focal epilepsy and absence seizures. GPT should be avoided in epilepsies with absence and myoclonic seizures, as recommended by the GDG of NICE, because it can aggravate these types of seizures [3].

\subsubsection{Lamotrigine (LTG)}

LTG was initially approved in the USA in 1994 for the treatment of FS, and in 1998, it received approval for use as adjunctive treatment of LGS. In 2003, it was approved for use as adjunctive therapy for FS in paediatric patients as young as 2 years of age. In 2004, LTG was approved for use as monotherapy for treatment of FS in adults when converting from VPA.

Whereas LTG or CBZ as monotherapy were equally effective in children and adults with GTCS (OR 1.37, $95 \%$ CI 0.74-2.56), LTG was less effective than CBZ in obtaining seizure freedom after 6 months in FS (OR 0.72, $95 \%$ CI 0.54-0.97) [8]. When a subgroup analysis was conducted by age categories, no differences were observed in children younger than 12 years old for efficacy (OR $0.86,95 \% \mathrm{CI} 0.46-1.60$ ) and tolerability measured as time to treatment withdrawal (HR 0.83, $95 \%$ CI 0.34-2.04). A review assessing the evidence for efficacy of add-on LTG versus placebo in paediatric and adult patients with refractory primary GTCS was unable to draw any conclusions [48]. Data on patients 2-20 years old show that LTG is more effective than placebo in controlling primary GTCS [49]. Adjunctive LTG reduced seizures in paediatric and adult patients with refractory focal epilepsy at the cost of some AEs [50]. The analysis limited to the 2-16 years age range showed OR to be 3.54 -fold higher than placebo in reference to a $50 \%$ seizure reduction [51]. Ataxia, dizziness, fatigue and nausea were reported with higher frequency than in the placebo group $[50,51]$. PiñaGarza et al. [52] reported LTG to be effective in reducing FS in a small group of patients aged 1-24 months. In an RCT enrolling 453 children, LTG was less effective than ETS and VPA against childhood absence epilepsy [36].

In a well-conducted RCT enrolling 169 individuals aged 3-25 years with LGS, add-on LTG was well tolerated and more effective than placebo against drop attacks $(P=0.01)$ and tonic-clonic seizures $(P=0.03)$, but not atypical absences $(P=0.96)$ [53].

LTG should be considered as a first-line drug for FS and GTCS. LTG, as monotherapy or in add-on, represents an alternative treatment for absence seizures if ETS and VPA are unsuitable, ineffective or not tolerated $[3,36]$. The drug may exacerbate both convulsive and myoclonic seizures in Dravet syndrome [54] and myoclonic seizures in juvenile myoclonic epilepsy [3]. Since the risk of LTG-related rash is much increased by rapid titration, this drug is not recommended when a rapid antiepileptic action is necessary.

\subsubsection{Levetiracetam (LEV)}

LEV is an AED that has been marketed in the USA and Europe since 2000. LEV can be used on its own in patients from 16 years of age with newly diagnosed epilepsy to treat FS with or without secondary generalization. It can also be used as an add-on to other AEDs to treat the following: FS with or without generalization in patients from 1 month of age; myoclonic seizures in patients from 12 years of age with juvenile myoclonic epilepsy; primary GTCS in patients from 12 years of age with idiopathic generalized epilepsy.

Mbizvo et al. [55] assessed the efficacy of LEV as adjunctive treatment for refractory focal epilepsy in a review including 11 RCTs, two of which totalled 296 children [56, 57]. LEV was significantly more effective than placebo in reducing seizure frequency more than $50 \%$ in both adults and children. In the two paediatric studies included in the review, $60 \mathrm{mg} / \mathrm{kg} /$ day was the effective dosage (RR 1.91, $95 \%$ CI 1.38-2.63) [56, 57]. More severe behavioural AEs were reported in children treated with LEV compared with placebo [58].

Similar results were obtained in a more recent metaanalysis including 13 RCTs that found a higher efficacy of add-on LEV versus placebo in reducing the frequency of 
seizures in mixed populations with focal and idiopathic generalized epilepsy [59]. Analysis of efficacy by subgroups of children with FS showed LEV to be effective in reducing seizure frequency more than $50 \%$ (OR 3.33, $95 \%$ CI 1.95-5.37) and achieving complete seizure control (OR 7.15, $95 \%$ CI 0.86-59.23). However, for the latter effect no statistical significance was reached.

Adjunctive therapy with LEV (dose $3000 \mathrm{mg} /$ day) was significantly more effective than placebo in reducing the frequency of myoclonic seizure ( 25 vs. $5 \%$, respectively, $P=0.004)$ in an RCT enrolling 122 adolescents and adults with previously uncontrolled idiopathic generalized epilepsy with myoclonic seizures [60].

LEV efficacy for the treatment of absence seizures was not proven in a multicentre RCT including 38 participants aged 4-16 years [61] in which there were $23.7 \%$ responders in the LEV group and $4.8 \%$ in the placebo group $(P=0.08)$. A small, underpowered, non-inferiority RCT of LEV compared with STM for the treatment of BECTS showed no conclusive results [62].

There is no evidence of efficacy supporting the use of LEV in adjunctive therapy, except for a small study including adolescents and adults with myoclonic seizures [60]. NICE considers its use only in children with refractory focal epilepsy [3]. LEV efficacy in BECTS and absence seizures is unproven $[61,62]$.

\subsubsection{Oxcarbazepine (OXC)}

In 2000, OXC was approved in the USA as adjunctive and monotherapy for adults and adjunctive therapy for children ages 4-16 years with FS.

A comparable profile in both efficacy (HR 1.04, $95 \%$ CI 0.78-1.39) and safety between OXC and CBZ in mixed populations with FS was reported in a Cochrane review including 723 participants from three studies [63]. When the analysis was limited to the paediatric population, OXC showed a better safety profile compared with CBZ, except for nausea or vomiting, or both (OR 3.15, $95 \%$ CI 1.39-7.14) [63]. OXC monotherapy was as effective (61\% seizure free) as PHT (60\%) in treating children and adolescents with newly diagnosed FS or GTCS [64]. The latter study was also included in a recent Cochrane review and is the only one with an exclusively paediatric population [65]. Adjunctive therapy with OXC (dose range of $6-51 \mathrm{mg}$ / $\mathrm{kg}$ /day) was significantly more effective than placebo in reducing seizure frequency ( 35 vs. $9 \%$, respectively) in a multicentre RCT enrolling 267 children and adolescents with refractory FS [66]. The most common AEs associated with OXC therapy were somnolence, dizziness, nausea and vomiting [66].

OXC is a viable alternative to CBZ and LTG in FS and GTCS. OXC is better tolerated than older AEDs (CBZ and
PHT), and has a lower potential for drug interactions. OXC should be used cautiously in patients with prior CBZ hypersensitivity because of their chemical and structural similarities. Like CBZ, OXC can aggravate absence and myoclonic seizures and should be avoided in epilepsies with these seizure types [3].

\subsubsection{Pregabalin $(P G B)$}

In the USA and Europe, PGB was approved in 2004 as adjunctive therapy for adult patients with FS. Zhou et al. [67] reviewed clinical data on PGB, which are limited to the adult population with newly diagnosed focal epilepsy. A comparison with LTG showed the latter to be superior to PGB in achieving remission at 6 months (seizure freedom), with a similar safety profile in both groups [67].

The superiority of adjunctive PGB versus placebo and its dose-dependent effects (from 50 to $600 \mathrm{mg} /$ day in different studies) were demonstrated in the analysis of six RCTs including a population of mostly adults with refractory focal epilepsy [68]. The sensitivity analysis and the best/worst case scenarios showed a drastic reduction in efficacy with low-dose PGB and reduced compliance for high doses [68]. A single study enrolling individuals more than 12 years old [69] confirmed the efficacy of PGB and its dose-dependent effects (seizure frequency reductions from baseline were $7 \%$ with placebo, $12 \%$ with $50 \mathrm{mg} /$ day, $34 \%$ with $150 \mathrm{mg} /$ day, $\quad 44 \%$ with $300 \mathrm{mg} /$ day, and $54 \%$ with $600 \mathrm{mg} /$ day). The use of PGB as adjunctive therapy should be considered only in refractory focal epilepsies and should be limited to the patient population referred to tertiary epilepsy centres [3]. Clinical practice suggests that PGB can aggravate absence and myoclonic seizures and should be avoided in epilepsies with these types of seizures, as recommended by the GDG of NICE [3].

\subsubsection{Tiagabine (TGB)}

In 1997, the FDA approved TGB as an adjunctive therapy for treating refractory FS in adults. The efficacy and safety of TGB in refractory focal epilepsy were assessed in a recent review [70] whose conclusions indicate that the drug, used as add-on, was more effective than placebo in 615 patients (two RCTs) aged $>12$ years old [71, 72]. The RR of more than $50 \%$ seizure reduction was 3.09 (95\% CI 1.65-5.79) in one study [71] and 4.20 (95\% CI 1.54-11.41) in another [72]. However, adding TGB to basic treatment was associated with an increase in AEs such as dizziness, fatigue, nausea, difficulty concentrating, nervousness and tremor [70]. The information regarding the efficacy and safety of TGB in children is inconclusive. 


\subsubsection{Topiramate (TPM)}

In the USA and Europe, TPM was initially (1996) approved as adjunctive therapy for adults and paediatric patients aged 2-16 years with FS or primary GTCS, and in patients 2 years of age and older with seizures associated with LGS. TPM is now also indicated as initial monotherapy in patients 2 years of age and older with FS or primary GTCS.

The efficacy of adjunctive TPM in the treatment of refractory focal epilepsy was analysed in a review including 1401 participants (11 RTCs) [73]. In mixed populations, TPM was more effective than placebo in reducing seizure frequency more than $50 \%$ (RR 2.97, $95 \%$ CI 2.38-3.72) and in obtaining seizure freedom (RR 3.41, $95 \%$ CI 1.37-8.51). However, several AEs were reported in patients on TPM (ataxia RR 2.29; concentration difficulties RR 7.81; paraesthesia RR 3.91; 'thinking abnormally' RR 5.70; weight loss RR 3.47). The only paediatric study, which included 86 patients aged 2-16 years, showed borderline efficacy $(50 \%$ reduction in seizure frequency RR 1.95, $95 \%$ CI 0.97-3.92; seizure freedom RR 2.20, $95 \%$ CI $0.42-11.36$ ) and a good efficacy/tolerability profile according to treatment withdrawal rates $(0 / 41$ in the TPM group and 2/45 in the placebo group) [74].

In a dose-controlled RCT of TPM as first-line therapy, the probability of being seizure free at 6 months in patients older than 6 years with FS and GTCS was $83 \%$ in the $400 \mathrm{mg} /$ day arm and $71 \%$ in the $50 \mathrm{mg} /$ day arm $(P=0.005)$. Seizure-free rates at 12 months were 76 and $59 \%$, respectively $(P=0.001)$ [75]. One wonders to what extent these results reflect drug efficacy or the natural history of a mixed population with new onset epilepsies, including a large number of individuals who would not have relapsed anyway during the trial period.

A double-blind, controlled study failed to demonstrate non-inferiority of TPM monotherapy compared with PHT in 261 individuals aged 12-65 years with 'newly diagnosed epilepsy' [76]. The rate of treatment discontinuation was slightly higher in the PHT arm. The study was generally inconclusive and did not allow precise indications, except a suggestion that TPM may be a useful option when treatment needs be started quickly.

Wheless et al. [77] reported TPM to be as effective and as safe as CBZ and VPA in treating mixed populations (only $19 \%$ of children and adolescents) with newly diagnosed focal epilepsy. Its efficacy in LGS was controversial according to one review [16] that included nine RCTs testing different drugs against placebo; no final analysis was possible because of heterogeneity of populations, therapies and outcomes. In one of the studies included in the review [78], enrolling 98 patients aged $1-30$ years, the percentage of patients with a greater than $50 \%$ reduction from baseline of major seizures (drop attacks and tonicclonic seizures) was superior in the TPM group (15/46 or $33 \%)$ compare with in the placebo group (4/50 or $8 \%$, $P=0.002$ ).

TPM is only recommended as add-on therapy in children with refractory focal epilepsy [73] and with LGS [16]. Handling and safety, which may be considered relevant factors when treatment should be started quickly, are its main advantages.

\subsubsection{Vigabatrin $(G V G)$}

GVG has been used in Europe for the treatment of infantile spasms since 1989. In 2009, VGB was approved by the FDA for use as monotherapy in the treatment of infantile spasms in children aged 1 month to 2 years. In 2010, GVG was also approved as add-on therapy for refractory focal epilepsy in adults when other options have failed. The efficacy of adjunctive GVG as compared with CBZ was assessed in a review including 734 participants (mixed populations) with refractory focal epilepsy from five RCTs of poor quality, as reported by the reviewers [11]. Two of these studies enrolled a paediatric population [9, 10]. A meta-analysis was impossible because of the heterogeneity of the outcomes considered in the studies, which found a comparable efficacy between GVG and CBZ, with higher rates of AEs for GVG [11]. Visual disturbances in a mixed population (more than 15 years old) were more frequent in patients treated with GVG (RR 15.68, 95\% CI 0.92-266.46) [11]. In the Sobaniec et al. [10] study, visual field defects in children were not significantly more frequent in the GVG group (2/26 patients) as compared with the CBZ group ( $0 / 28$ patients), perhaps because of the small number of patients and AEs (0 vs. 2).

GVG was more effective than placebo in treating refractory focal epilepsy as reported in a recent review analysing 11 RCTs in which GVG doses ranged from 1000 to $6000 \mathrm{mg} / \mathrm{day}$ [79]. The same results were obtained in a paediatric population (three studies included in the review), with higher efficacy but more AEs in the GVG groups (2000-3000 mg/day) as compared with placebo [80-82].

Difficulties in conducting a meta-analysis are highlighted in the review by Hancock et al. [23] that analyses 18 small and poor quality RCTs regarding several treatments of West syndrome. A non-significant superiority of GVG compared with placebo in controlling spasms was reported in a small RCT including 40 individuals (OR 4.05, $95 \%$ CI 0.93-17.52) [82]. GVG was less effective compared with hormonal treatment (prednisolone or tetracosactide depot) (OR 0.42, $95 \%$ CI 0.21-0.80) in controlling infantile spasms [27-29]. The superiority of GVG compared with hydrocortisone (OR 13.80, $95 \%$ CI 2.21-86.35) was documented in patients with tuberous 
sclerosis, suggesting that GVG should be considered as the first-line choice when spasms are caused by this specific aetiology [27, 83].

Considering the high prevalence of visual field defects $[10,11]$, GVG should be limited to children with infantile spasms. GVG should be considered as adjunctive therapy in treating refractory focal epilepsy only by tertiary epilepsy specialists if first-line treatments are ineffective or not tolerated [3]. Clinical practice suggests that GVG can aggravate absence and myoclonic seizures and should be avoided in epilepsies with these types of seizures, as recommended by the GDG of NICE [3].

\subsubsection{Zonisamide (ZNS)}

In the USA, ZNS was introduced in 2000 to treat adult patients with FS, including those with secondary generalization. In Europe, ZNS is used on its own in newly diagnosed adults and as an 'add-on' therapy in adults and children aged 6 years and above already receiving other AEDs. ZNS was more effective than placebo in reducing seizure frequency by more than $50 \%$ (RR 1.92, $95 \%$ CI 1.52-2.42) when used as an add-on for the treatment of refractory focal epilepsy as reported in a review including almost 1000 patients, mostly adults, from five RCTs [84]. In this review, the risk of anorexia was threefold in the ZNS group compared with placebo, as also observed in a pooled analysis of data from 17 studies including 398 individuals less than 16 years old [85]. Similar results on the efficacy of ZNS compared with placebo were reported in an RCT including 207 children and adolescents with refractory focal epilepsy (a reduction of seizure frequency greater than $50 \%$ was observed in $50 \%$ of the ZNS group and in $31 \%$ of the placebo group) [86]. ZNS was more effective than placebo when considering only complex FS, which affected more than $50 \%$ of the population studied, leading to problems of directness (external validity). In the open-label extension phase of the study an abnormal excess of AEs related to weight loss was observed in the placebo group [87].

Initial evidence suggests potential efficacy and a good safety profile for adjunctive ZNS in focal epilepsy in children [86, 87].

\subsection{Third-Generation AEDs}

\subsubsection{Eslicarbazepine Acetate (ESL)}

ESL was approved in Europe (2009) and the USA (2013) as adjunctive therapy for the treatment of FS in adults. The efficacy and tolerability of ESL when used as an add-on treatment for refractory focal epilepsy was evaluated in a Cochrane review including four RCTs for a total of 1146 participants [88]. In all RCTs, ESL was tested against placebo only in adults, showing a good efficacy in reducing seizure frequency more than $50 \%$ (RR 1.86, $95 \%$ CI 1.46-2.36), which was not confirmed in the worst scenarios simulated by the reviewers (RR $0.89,95 \%$ CI $0.75-1.05$ ) [88]. ESL also showed a dose-dependent effect and a number of AEs (especially diplopia) that affected adherence to treatment [88].

No information is available for the paediatric population, with the exception of a study evaluating ESL pharmacokinetics [89].

\subsubsection{Lacosamide (LCS)}

In 2008, LCS was approved in the USA and Europe as adjunctive treatment of FS, with or without secondary generalization, in adults. LCS has not been studied specifically in children less than 16 years old. A good efficacy of adjunctive LCS for FS in mixed populations ( $\geq 16$ years) was reported in two RCTs, in which no age subgroup analysis was performed [90, 91]. LCS is a promising molecule since it prompted a $50 \%$ reduction in seizure frequency in one-third of patients taking $200 \mathrm{mg} /$ day $(P=0.07)$ and in approximately $40 \%$ of those taking $400 \mathrm{mg} /$ day $(P=0.01)$ [90]. Dose-dependent efficacy was also reported in a different study [91]. The $50 \%$ responder rate was $18.3 \%$ for placebo, $38.3 \%$ for LCS $400 \mathrm{mg} /$ day and $41.2 \%$ for LCS $600 \mathrm{mg} /$ day for all seizure types [91]. However, increased AEs were reported with higher LCS dosages. No information is available about the use of LCS in paediatric populations.

\subsubsection{Perampanel (PER)}

In the USA and Europe, PER was approved as add-on therapy to treat adults and children from 12 years of age with FS with or without secondary generalization. PER is also used from 12 years of age to treat primary GTCS associated with primary generalized epilepsy.

Three RCTs assessed both efficacy and safety of adjunctive PER in mixed populations (age $>12$ years), mostly adults, with FS with or without secondary generalization [92-94]. In two of these studies [90, 91], the efficacy of $8 \mathrm{mg} /$ day and $12 \mathrm{mg} /$ day of PER was tested versus placebo with conflicting results. In the study by French et al. [93], there were no differences in the responder rate (percentage of patients achieving a $50 \%$ or greater reduction in seizure frequency) amongst the three groups (placebo $26.4 \%$, PER $8 \mathrm{mg} /$ day $37.6 \%$ and PER $12 \mathrm{mg} /$ day $36.1 \%$ ). In a second study [94] with the same inclusion criteria, PER showed better efficacy (percentage of patients achieving a $50 \%$ or greater reduction in seizure frequency) compared with placebo, regardless of the dosage (placebo $14.7 \%$, PER $8 \mathrm{mg} /$ day $33.3 \%$, PER $12 \mathrm{mg} /$ day $33.9 \%$ ). 
A recent pooled dose-response analysis of the three RCTs concluded that a PER dose of $12 \mathrm{mg} / \mathrm{day}$, although associated with higher overall rates of discontinuation due to AEs, may produce additional therapeutic benefits in some patients who do not fully respond to doses up to $8 \mathrm{mg} / \mathrm{day}$ and who tolerate the higher dose [95]. The most common AEs observed were dizziness, gait disturbance, somnolence, fatigue, falls, irritability and suicidal behaviour [95]. A by-age subgroup analysis was not reported in any of these studies, thus limiting the directness of the PER efficacy profile in the paediatric population.

\subsubsection{Retigabine $(R T G)$}

In 2011, RTG was approved in the USA and Europe for the treatment of adults with refractory FS, with or without secondary generalization, in combination with other AEDs. The efficacy and safety information on RTG is limited to adults with refractory focal epilepsy. In a review based on a structured search of the literature, including three RCTs, of which one was phase II, RTG showed good efficacy for a dosage higher than $600 \mathrm{mg} / \mathrm{day}$, but its use was burdened by AEs [96]. In one study, the responder rate was higher than in the placebo group only using 900 and $1200 \mathrm{mg} / \mathrm{day}$ [97]. Some of the observed AEs, such as retinal pigmentation and urinary tract infections, are peculiar to the drug. The efficacy and safety of RTG in children are far from being defined.

\subsubsection{Rufinamide (RUF)}

RUF was approved in Europe (2007) and in the USA (2008) for use as adjunctive treatment of seizures associated with LGS in children 4 years and older and in adults.

The efficacy and safety of adjunctive RUF in refractory focal epilepsy were evaluated in an RCT enrolling 357 individuals aged $12-80$ years, $10 \%$ being in the paediatric age range [98]. The efficacy, in terms of seizure reduction and additional clinical endpoints, was higher in the RUF group (50\% or greater reduction in seizure frequency 32.5 vs. $14.3 \%$ in the placebo group); at baseline, secondarily generalized seizures were more frequently reported in the RUF group than in the placebo group (43.2 vs. $36.1 \%)$. In this study, a small proportion of patients in both arms (approximately $17 \%$ ) experienced a $25 \%$ increase in seizure frequency. No subgroup analysis by age was reported by the authors. Confusion (26\%), headache $(16 \%)$, somnolence $(12 \%)$, tremor $(4 \%)$, dizziness $(4 \%)$ and convulsions (4\%) were the most frequent AEs observed [98].

A recent review focused on the efficacy of different drugs (RUF, FBM, LTG, TPM) in treating LGS and included AEDs commonly used in this severe form of epilepsy [16]. Because of the high heterogeneity of the studies included in the analysis, the review failed to demonstrate the superiority of any of the four AEDs considered. Each AED included in the review by Hancock et al. [16] showed a similar efficacy profile when compared with placebo. Adjunctive RUF was more effective compared with placebo in one RCT, included in the Hancock review, in which 138 individuals with LGS were enrolled [99]. A statistically significant decrease in seizure frequency was observed in the study group, particularly for tonic-atonic (42.5 vs. $1.4 \%$ ) and FS (71.9 vs. $11.1 \%)$. Similar results and an enduring efficacy were demonstrated in the following open-label extension phase of the study [100].

Frequent, though mild, AEs (somnolence, vomiting and headache) were observed in a re-analysis of paediatric populations treated with RUF and included in clinical trials [101]. These results are confirmed in a more recent metaanalysis including more than 1200 adult and paediatric patients treated with RUF [102]. In a cost-effectiveness analysis, RUF showed a better pharmacological profile as compared with LTG and TPM when used as an add-on in children with LGS [103]. The results were obtained with a simulation model in which the primary outcome measure was the percentage of successfully treated patients, defined as a more than $50 \%$ reduction in the frequency of total seizures and drop attacks [103].

RUF is only recommended as add-on therapy in children with refractory focal epilepsy [98] and in LGS [16]. Handling and safety are its main advantages.

\subsubsection{Stiripentol (STP)}

In Europe, STP is used as an add-on to CLB and VPA in children with severe myoclonic epilepsy of infancy (SMEI or Dravet syndrome) to treat GTCS when these are not adequately controlled with these drugs. Since SMEI is considered a 'rare disease', STP was designated as an 'orphan medicine' in 2001. STP received a full marketing authorization in 2014. STP is not an FDA-approved drug.

The efficacy of STP in focal epilepsy needs to be investigated further. In the only clinical study [104] assessing the efficacy of adjunctive STP in 32 children with refractory focal epilepsy, no differences were found compared with placebo in terms of seizure increase by at least $50 \%$ after randomization (primary endpoint) compared with baseline (6/17 in the STP group vs. 8/15 in the placebo group). Furthermore, several methodological limitations make the study inadequate to support the use of STP as add-on treatment for refractory focal epilepsy, including study design ('responder enriched'), short follow-up ( 2 months), and the small number of patients enrolled [104]. In a systematic review assessing the efficacy and 
tolerability of STP as add-on treatment for refractory focal epilepsy [105], only including one study [101] and considering the secondary endpoints $(50 \%$ or greater reduction in seizure frequency and seizure freedom), no superior efficacy of STP compared with placebo could be demonstrated (RR 1.51, $95 \%$ CI 0.81-2.82, and RR 1.18, $95 \%$ CI 0.31-4.43, respectively).

A recent review analysed two RCTs evaluating the efficacy and tolerability of STP versus placebo in 64 children with SMEI or Dravet syndrome [106]. Compared with patients on placebo, those receiving STP were more likely to be seizure free (RR 7.93, $95 \%$ CI 1.52-41.21) or experience a $50 \%$ or greater reduction in seizure frequency (RR 10.40, 95 \% CI 2.64-40.87) [107, 108]. Only one study explicitly reported AEs, which were more frequent in patients treated with STP [107].

STP is promising in the treatment of Dravet syndrome. However, further studies are needed to assess its long-term efficacy and tolerability.

\subsection{Cannabinoids}

Cannabinoids are not approved for epilepsy in the USA and Europe. The efficacy of cannabidiol was recently analysed in a systematic review including four poor quality (Cochrane judgment) RCTs (48 patients) that lacked the basic minimum required information [109]. The four reports only addressed the secondary outcome of AEs; none of the patients in the treatment groups had any AEs. More studies are needed to prove the efficacy and safety of cannabidiol in epilepsy [109].

\section{Discussion}

Most children with epilepsy can be divided into four main aetiological and prognostic groups, whose early identification will greatly influence treatment choices [110]. The first group is the benign focal epilepsies-e.g. benign rolandic epilepsy (20-30\% of patients) - in which remission occurs after a few years and treatment can often be avoided. The second group is the pharmacosensitive epilepsies-e.g. most children with absence epilepsy (30\% of patients) - in which seizure control is easily achieved by ETS or VPA and spontaneous remission occurs after a few years. The third one is the so-called pharmacodependent epilepsies (20\% of patients), in which drug treatment will control seizures but no spontaneous remission occurs, e.g. juvenile myoclonic epilepsy, which is ideally treated with VPA, and a subset of symptomatic focal epilepsies, which will respond to initial CBZ treatment. Drug withdrawal is followed by relapse and treatment will likely be lifelong. The fourth group is the pharmacoresistant (or refractory) epilepsies, with poor prognosis (13-17\% of patients). This subgroup includes the so-called epileptic encephalopathies (e.g. West syndrome, Dravet syndrome and LGS) and a subset of children with focal symptomatic epilepsy. Treatment choices in these conditions are more complex and imply different, relatively specific first-line choices and second-line options. Overall, the place of newer generation AEDs in paediatric epilepsy is still poorly defined and mainly limited to second-line options because of poor evidence concerning both efficacy and safety.

Most phase III trials conducted to date have major methodological limitations, preventing any meaningful conclusions on comparative efficacy between old and new AEDs in children. As expected, there is more (and more detailed) information on older drugs. Only some of the newer drugs benefit from robust experimental studies of efficacy and, more importantly, of post-marketing studies with long-duration follow-up, which are the only studies capable of obtaining appropriate information related to the safety profile. In many cases, the information on the appropriateness of use of AEDs in children derives from adult or mixed-population studies, with obvious problems of directness of the results, which should be addressed on a case-by-case basis. The recent development of the PIP (Paediatric Investigation Plan) by Regulation (EC) no. 1901/2006 of the European Parliament and of the Council, which requires planning for the complete development path of paediatric medicinal products, should bridge the gap between what is already known for adults and what is yet to be learned for children.

Most of the recent studies include heterogeneous populations with a small number of paediatric patients, usually older than 12 years of age, and lack by-age subgroup analyses. Heterogeneity in the definition and reporting of outcomes (i.e. $50 \%$ or greater reduction in seizure frequency, time to 12-month remission or time to first seizure) characterizes most of the RCTs, making any meta-analysis of primary studies difficult. Furthermore, while some trials consider the time to first seizure from the date of randomization, others consider the date of achieving maintenance dose, thus complicating the analysis of event-free survival. Different epilepsy syndromes and aetiologies are often lumped together, and trial design is neither powered for conducting subgroup analysis nor developed with follow-up periods appropriate to the natural history of the various epilepsies. Moreover, most of the recently introduced AEDs have been tested in placebo-controlled adjunctive therapy trials performed on patients who did not respond to the first- or subsequent-line drugs and whose treatment failures with other previous AEDs, and the reasons for them (appropriateness of treatment, dosing, compliance), were poorly documented. The risk of including potential responders to first- and subsequent-line therapy 
might generate an over-estimation of the efficacy of the drug under trial. Although RCTs using placebo as a comparator fulfil the design criteria for marketing authorization (EMA and FDA), the use of a drug in clinical practice would require evidence in line with the Comparative Effectiveness Research (CER) paradigm [111].

Patients enrolled in the studies should be truly resistant to first- and subsequent-line therapies in order to select those with no further treatment options. Only in these circumstances would placebo-controlled trials be truly useful for developing the therapeutic armamentarium. In the absence of these conditions, the control group should be allocated to the best treatment available.

Finally, the majority of RCTs exclude children younger than 2 years, who sadly experience the most severe epileptic encephalopathies with refractory seizures. These severe forms of epilepsy result from many different, often genetic, aetiologies. Consequently, in spite of a similar clinical presentation, they have highly different pathophysiological bases. The research agenda should consider this little known but very important area and plan the development of pharmacological trials also considering aetiological subgroups, as well as pharmacogenomic influences.

\section{Conclusion}

Evidence concerning the efficacy and safety profile of older AEDs has been accumulated through studies and clinical observations gathered over many years. The superiority of the new drugs in terms of efficacy has only been reported versus placebo. Overall, newer molecules are deemed to cause fewer AEs and to be more manageable [112]. However, safety information is based on short follow-up periods and on RCTs sized on the basis of efficacy outcomes, which do not properly assess safety in the long term. Evidence on the efficacy of newer AEDs, especially in the paediatric age range, has only been fully explored in a few instances. Current data are insufficient to weigh the risk-benefit balance of using ESL, LCS, PER, PGB, RTG and TGB in children with epilepsy. The considerably higher costs of newer molecules should also be taken into account in the decision-making process.

\section{Compliance with Ethical Standards}

Funding No payment was received for the publication of this review. The Open Access fees were paid by the Meyer Foundation.

Conflict of interest Anna Rosati, Salvatore De Masi and Renzo Guerrini state no conflict of interest.
Open Access This article is distributed under the terms of the Creative Commons Attribution-NonCommercial 4.0 International License (http://creativecommons.org/licenses/by-nc/4.0/), which permits any noncommercial use, distribution, and reproduction in any medium, provided you give appropriate credit to the original author(s) and the source, provide a link to the Creative Commons license, and indicate if changes were made.

\section{References}

1. Wirrell EC. Predicting pharmacoresistance in pediatric epilepsy. Epilepsia. 2013;54(Suppl 2):19-22.

2. McCabe PH. New anti-epileptic drugs for the 21st century. Expert Opin Pharmacother. 2000;1:633-74.

3. The Epilepsies. The diagnosis and management of the epilepsies in adults and children in primary and secondary care. London: Published by the National Clinical Guideline Centre at The Royal College of Physicians; 2012. http://www.nice.org.uk/ guidance/cg137. Accessed 24 Sep 2014.

4. de Silva M, MacArdle B, McGowan M, et al. Randomised comparative monotherapy trial of phenobarbitone, phenytoin, carbamazepine, or sodium valproate for newly diagnosed childhood epilepsy. Lancet. 1996;347:709-13.

5. Tudur Smith C, Marson AG, Clough HE, Williamson PR. Carbamazepine versus phenytoin monotherapy for epilepsy. Cochrane Database Syst Rev. 2002;(2):1-22. Art. No.: CD001911.

6. Tudur Smith C, Marson AG, Williamson PR. Carbamazepine versus phenobarbitone monotherapy for epilepsy. Cochrane Database Syst Rev. 2003;(1):1-22. Art. No.: CD001904.

7. Marson AG, Williamson PR, Clough H, Hutton JL, Chadwick DW, Epilepsy Monotherapy Trial Group. Carbamazepine versus valproate monotherapy for epilepsy: a meta-analysis. Epilepsia. 2002;43(5):505-13.

8. Gamble CL, Williamson PR, Marson AG. Lamotrigine versus carbamazepine monotherapy for epilepsy. Cochrane Database Syst Rev. 2006;(1):1-45. Art. No.: CD001031.

9. Zamponi N, Cardinali C. Open comparative long-term study of vigabatrin vs carbamazepine in newly diagnosed partial seizures in children. Arch Neurol. 1999;56:605-7.

10. Sobaniec W, Kulak W, Strzelecka J, Smigielska-Kuzia J, Boćkowski L. A comparative study of vigabatrin vs. carbamazepine in monotherapy of newly diagnosed partial seizures in children. Pharmacol Rep. 2005;57:646-53.

11. Xiao Y, Gan L, Wang J, Luo M, Luo H. Vigabatrin versus carbamazepine monotherapy for epilepsy. Cochrane Database Syst Rev. 2012;(1):1-37. Art. No.: CD008781.

12. Guerrini R, Belmonte A, Genton P. Antiepileptic drug-induced worsening of seizures in children. Epilepsia. 1998;39(Suppl 3):S2-10.

13. Canadian Study Group for Childhood Epilepsia. Clobazam has equivalent efficacy to carbamazepine and phenytoin as monotherapy for childhood epilepsy. Epilepsia. 1998;39(9): 952-9.

14. Keene DL, Whiting S, Humphrys P. Clobazam as an add on drug in the treatment of refractory epilepsy of childhood. Can J Neurol Sci. 1990;17:317-9.

15. Cramer J, Sapin C, François C. Indirect comparison of clobazam and other therapies for Lennox-Gastaut syndrome. Acta Neurol Scand. 2013;128:91-9.

16. Hancock EC, Cross JH. Treatment of Lennox-Gastaut syndrome. Cochrane Database Syst Rev. 2009;(2):1-43. Art. No.: CD003277. 
17. Conry JA, Ng YT, Paolicchi JM, et al. Clobazam in the treatment of Lennox-Gastaut syndrome. Epilepsia. 2009;50:1158-66.

18. Ng YT, Conry JA, Drummond R, Stolle J, Weinberg MA, OV1012 Study Investigators. Randomized, phase III study results of clobazam in Lennox-Gastaut syndrome. Neurology. 2011;77:1473-81.

19. Conry JA, Ng YT, Kernitsky L, et al. Stable dosages of clobazam for Lennox-Gastaut syndrome are associated with sustained drop-seizure and total-seizure improvements over 3 years. Epilepsia. 2014;55:558-67.

20. Riss J, Cloyd J, Gates J, Collins S. Benzodiazepines in epilepsy: pharmacology and pharmacokinetics. Acta Neurol Scand. 2008;118:69-86.

21. Mikkelsen B, Birket-Smith E, Bradt S, et al. Clonazepam in the treatment of epilepsy. A controlled clinical trial in simple absences, bilateral massive epileptic myoclonus, and atonic seizures. Arch Neurol. 1976;33:322-5.

22. Dahlin M, Knutsson E, Amark $\mathrm{P}$, Nergårdh A. Reduction of epileptiform activity in response to low-dose clonazepam in children with epilepsy: a randomized double-blind study. Epilepsia. 2000;41:308-15.

23. Hancock EC, Osborne JP, Edwards SW. Treatment of infantile spasms. Cochrane Database Syst Rev. 2013;(6):1-69. Art. No.: CD001770.

24. Hrachovy RA, Frost JD, Glaze DG. High-dose, long-duration versus low-dose, short-duration corticotropin therapy for infantile spasms. J Pediatr. 1994;124:803-5.

25. Baram TZ, Mitchell WG, Tournay A, Snead OC, Hanson RA, Horton EJ. High-dose corticotropin (ACTH) versus prednisone for infantile spasms: a prospective, randomised, blinded study. Pediatrics. 1996;97:375-9.

26. Yanagaki S, Oguni H, Hayashi K, et al. A comparative study of high-dose and low-dose ACTH therapy for West syndrome. Brain Dev. 1999;21(7):461-7.

27. Chiron C, Dumas C, Jambaque I, Mumford J, Dulac O. Randomized trial comparing vigabatrin and hydrocortisone in infantile spasms due to tuberous sclerosis. Epilepsy Res. 1997;26:389-95.

28. Lux AL, Edwards SW, Hancock E, et al. The United Kingdom Infantile Spasms Study comparing vigabatrin with prednisolone or tetracosactide at 14 days: a multicentre, randomised controlled trial. Lancet. 2004;364:1173-8.

29. Vigevano F, Cilio MR. Vigabatrin versus ACTH as first line treatment for infantile spasms: a randomised prospective study. Epilepsia. 1997;38:1270-4.

30. Askalan R, Mackay M, Brian J, et al. Prospective preliminary analysis of the development of autism and epilepsy in children with infantile spasms. J Child Neurol. 2003;18(3):165-70.

31. Posner EB, Mohamed KK, Marson AG. Ethosuximide, sodium valproate or lamotrigine for absence seizures in children and adolescents. Cochrane Database Syst Rev. 2005;(4):1-17. Art. No.: CD003032.

32. Callaghan N, O'Hare J, O'Driscoll D, O’Neill B, Daly M. Comparative study of ethosuximide and sodium valproate in the treatment of typical absence seizures (petit mal). Dev Med Child Neurol. 1982;24:830-6.

33. Sato S, White BG, Penry JK, Dreifuss FE, Sackellares JC, Kupferberg HJ. Valproic acid versus ethosuximide in the treatment of absence seizures. Neurology. 1982;32(2):157-63.

34. Martinovic Z. Comparison of ethosuximide with sodium valproate as monotherapies of absence seizures. Advances in Epileptology: XIVth Epilepsy International Symposium. New York: Raven Press; 1983:301-5.

35. Coppola G, Auricchio G, Federico R, Carotenuto M, Pascotto A. Lamotrigine versus valproic acid as first-line monotherapy in newly diagnosed typical absence seizures: an open-label, randomized, parallel-group study. Epilepsia. 2004;45:1049-53.

36. Glauser TA, Cnaan A, Shinnar S, et al. Ethosuximide, valproic acid, and lamotrigine in childhood absence epilepsy. N Engl J Med. 2010;362(9):790-9.

37. Nolan SJ, Tudur Smith C, Pulman J, Marson AG. Phenobarbitone versus phenytoin monotherapy for partial onset seizures and generalised onset tonic-clonic seizures. Cochrane Database Syst Rev. 2013;(1):1-35. Art. No.:CD002217.

38. Nolan SJ, Marson AG, Pulman J, Tudur Smith C. Phenytoin versus valproate monotherapy for partial onset seizures and generalised onset tonic-clonic seizures. Cochrane Database Syst Rev. 2013;(8):1-70. Art. No.: CD001769.

39. Milburn-McNulty P, Powell G, Sills GJ, Marson AG. Sulthiame add-on therapy for epilepsy. Cochrane Database Syst Rev. 2013;(3):1-16. Art. No.: CD009472.

40. Debus OM, Kurlemann G. Sulthiame in the primary therapy of West syndrome: a randomised double blind placebo-controlled add-on trial on baseline pyridoxine medication. Epilepsia. 2004;45:103-8.

41. Rating D, Wolf C, Bast T. Sulthiame as monotherapy in children with benign childhood epilepsy with centrotemporal spikes: a 6-month randomized, double-blind, placebo-controlled study. Epilepsia. 2000;41(10):1284-8.

42. Milburn-McNulty P, Powell G, Sills GJ, Marson AG. Sulthiame monotherapy for epilepsy. Cochrane Database Syst Rev. 2014;(3):1-29. Art. No.: CD010062.

43. Shi LL, Dong J, NiH, Geng J,Wu T. Felbamate as an add-on therapy for refractory epilepsy. Cochrane Database Syst Rev. 2011;(1):1-14. Art. No.: CD008295.

44. The Felbamate Study Group in Lennox-Gastaut Syndrome. Efficacy of felbamate in childhood epileptic encephalopathy (Lennox-Gastaut syndrome). N Engl J Med. 1993;328:29-33.

45. Appleton R, Fichtner K, LaMoreaux L, et al. Gabapentin as addon therapy in children with refractory partial seizures: a 12-week, multicentre, double-blind, placebo-controlled study. Gabapentin Paediatric Study Group. Epilepsia. 1999;40(8): 1147-54.

46. Al-Bachari S, Pulman J, Hutton JL, Marson AG. Gabapentin add-on for drug-resistant partial epilepsy. Cochrane Database Syst Rev. 2013;(7):1-43. Art. No.: CD001415.

47. Trudeau V, Myers S, LaMoreaux L, et al. Gabapentin in naive childhood absence epilepsy: results from two double-blind, placebo-controlled, multicenter studies. J Child Neurol. 1996;11:470-5.

48. Tjia-Leong E, Leong K, Marson AG. Lamotrigine adjunctive therapy for refractory generalized tonic-clonic seizures. Cochrane Database Syst Rev. 2010;(12):1-16. Art. No.: CD007783.

49. Trevathan E, Kerls SP, Hammer AE, Vuong A, Messenheimer JA. Lamotrigine adjunctive therapy among children and adolescents with primary generalized tonic-clonic seizures. Pediatrics. 2006;118:e371-8.

50. Ramaratnam S, Marson AG, Baker GA. Lamotrigine add-on for drug-resistant partial epilepsy. Cochrane Database Syst Rev. 2001;(3):1-37. Art. No.: CD001909.

51. Duchowny M, Pellock JM, Graf WD, et al. A placebo-controlled trial of lamotrigine add-on therapy for partial seizures in children. Lamictal Pediatric Partial Seizure Study Group. Neurology. 1999;53(8):1724-31.

52. Piña-Garza JE, Levisohn $\mathrm{P}$, Gucuyener $\mathrm{K}$, et al. Adjunctive lamotrigine for partial seizures in patients aged 1 to 24 months. Neurology. 2008;70:2099-108.

53. Motte J, Trevathan E, Arvidsson JF, Barrera MN, Mullens EL, Manasco P. Lamotrigine for generalized seizures associated 
with the Lennox-Gastaut syndrome. Lamictal Lennox-Gastaut Study Group. N Engl J Med. 1997;337(25):1807-12.

54. Guerrini R, Dravet C, Genton P, Belmonte A, Kaminska A, Dulac O. Lamotrigine and seizure aggravation in severe myoclonic epilepsy. Epilepsia. 1998;39:508-12.

55. Mbizvo GK, Dixon P, Hutton JL, Marson AG. Levetiracetam add-on for drug-resistant focal epilepsy: an updated Cochrane Review. Cochrane Database Syst Rev. 2012;(9):1-76. Art. No.: CD001901.

56. Glauser TA, Ayala R, Elterman RD, et al. Double-blind placebo-controlled trial of adjunctive levetiracetam in pediatric partial seizures. Neurology. 2006;66(11):1654-60.

57. Levisohn PM, Mintz M, Hunter SJ, Yang H, Jones J, N01103 Levetiracetam Study Group. Neurocognitive effects of adjunctive levetiracetam in children with partial-onset seizures: a randomized, double-blind, placebo-controlled, noninferiority trial. Epilepsia. 2009;50(11):2377-89.

58. de la Loge C, Hunter SJ, Schiemann J, Yang HC. Assessment of behavioral and emotional functioning using standardized instruments in children and adolescents with partial-onset seizures treated with adjunctive levetiracetam in a randomized, placebo-controlled trial. Epilepsy Behav. 2010;18:291-8.

59. Fang Y, Wu X, Xu L, et al. Randomized-controlled trials of levetiracetam as an adjunctive therapy in epilepsy of multiple seizure types. J Clin Neurosci. 2014;21:55-62.

60. Noachtar S, Andermann E, Meyvisch P, et al. Levetiracetam for the treatment of idiopathic generalized epilepsy with myoclonic seizures. Neurology. 2008;70(8):607-16.

61. Fattore C, Boniver C, Capovilla G, et al. A multicenter, randomized, placebo-controlled trial of levetiracetam in children and adolescents with newly diagnosed absence epilepsy. Epilepsia. 2011;52:802-9.

62. Borggraefe I, Bonfert M, Bast $\mathrm{T}$, et al. Levetiracetam vs. sulthiame in benign epilepsy with centrotemporal spikes in childhood: a double-blinded, randomized, controlled trial (German HEAD Study). Eur J Paediatr Neurol. 2013;17:507-14.

63. Koch MW, Polman SKL. Oxcarbazepine versus carbamazepine monotherapy for partial onset seizures. Cochrane Database Syst Rev. 2009;(4):1-21. Art. No.: CD006453.

64. Guerreiro MM, Vigonius U, Pohlmann H, et al. A double-blind controlled clinical trial of oxcarbazepine versus phenytoin in children and adolescents with epilepsy. Epilepsy Res. 1997;27:205-13.

65. Nolan SJ, Muller M, Tudur Smith C, Marson AG. Oxcarbazepine versus phenytoin monotherapy for epilepsy. Cochrane Database Syst Rev. 2013;(5):1-54. Art. No.: CD003615.

66. Glauser TA, Nigro M, Sachdeo R, et al. Adjunctive therapy with oxcarbazepine in children with partial seizures. The Oxcarbazepine Pediatric Study Group. Neurology. 2000;54:2237-44.

67. Zhou Q, Zheng J, Yu L, Jia X. Pregabalin monotherapy for epilepsy. Cochrane Database Syst Rev. 2012;(10):1-47. Art. No.: CD009429.

68. Pulman J, Hemming K, Marson AG. Pregabalin add-on for drugresistant partial epilepsy. Cochrane Database Syst Rev. 2014;(3):1-65. Art. No.: CD005612.

69. French JA, Kugler AR, Robbins JL, Knapp LE, Garofalo EA. Dose-response trial of pregabalin adjunctive therapy in patients with partial seizures. Neurology. 2003;60(10):1631-7.

70. Pulman J, Hutton JL, Marson AG. Tiagabine add-on for drugresistant partial epilepsy. Cochrane Database Syst Rev. 2014;(2):1-41. Art. No.: CD00190.

71. Sachdeo RC, Leroy RF, Krauss GL, et al. Tiagabine therapy for complex partial seizures: a dose-frequency study. Arch Neurol. 1997;54:595-601.

72. Uthman BM, Rowan AJ, Ahmann PA, et al. Tiagabine for complex partial seizures: a randomized, add-on, dose-response trial. Arch Neurol. 1998;55:56-62.
73. Pulman J, Jette N, Dykeman J, Hemming K, Hutton JL, Marson AG. Topiramate add-on for drug-resistant partial epilepsy. Cochrane Database Syst Rev. 2014;(2):1-52. Art. No.: CD001417.

74. Elterman RD, Glauser TA, Wyllie E, Reife R, Wu SC, Pledger G. A double-blind, randomized trial of topiramate as adjunctive therapy for partial-onset seizures in children. Topiramate YP Study Group. Neurology. 1999;52:1338-44.

75. Arroyo S, Dodson WE, Privitera MD, et al. Randomized dosecontrolled study of topiramate as first-line therapy in epilepsy. Acta Neurol Scand. 2005;112:214-22.

76. Ramsay E, Faught E, Krumholz A, et al. Efficacy, tolerability, and safety of rapid initiation of topiramate versus phenytoin in patients with new-onset epilepsy: a randomized double-blind clinical trial. Epilepsia. 2010;51:1970-7.

77. Wheless JW, Neto W, Wang S, EPMN-105 Study Group. Topiramate, carbamazepine, and valproate monotherapy: double-blind comparison in children with newly diagnosed epilepsy. J Child Neurol. 2004;19(2):135-41.

78. Sachdeo RC, Glauser TA, Ritter F, Reife R, Lim P, Pledger G. A double-blind, randomized trial of topiramate in Lennox-Gastaut syndrome. Topiramate YL Study Group. Neurology. 1999;52:1882-7.

79. Hemming K, Maguire MJ, Hutton JL, Marson AG. Vigabatrin for refractory partial epilepsy. Cochrane Database Syst Rev. 2013;(1):1-36. Art. No.: CD007302.

80. Grunewald RA, Thompson PJ, Corcoran R, Corden Z, Jackson GD, Duncan JS. Effects of vigabatrin on partial seizures and cognitive function. J Neurol Neurosurg Psychiatry. 1994;57:1057-63.

81. Loiseau P, Hardenberg JP, Pestre M, Guyot M, Schechter PJ, Tell GP. Double blind, placebo controlled study of vigabatrin (gamma vinyl GABA) in drug resistant epilepsy. Epilepsia. 1986;27:115-20.

82. Tassinari CA, Michelucci R, Ambrosetto G, Salvi F. Double blind study of vigabatrin in the treatment of drug resistant epilepsy. Arch Neurol. 1987;44:907-10.

83. Appleton RE, Peters ACB, Mumford JP, Shaw DE. Randomised, placebo-controlled study of vigabatrin as first-line treatment of infantile spasms. Epilepsia. 1999;40:1627-33.

84. Carmichael K, Pulman J, Lakhan SE, Parikh P, Marson AG. Zonisamide add-on for drug-resistant partial epilepsy. Cochrane Database Syst Rev. 2013;(12):1-38. Art. No.: CD001416.

85. Cross JH, Auvin S, Patten A, Giorgi L. Safety and tolerability of zonisamide in paediatric patients with epilepsy. Eur J Paediatr Neurol. 2014;18(6):747-58.

86. Guerrini R, Rosati A, Segieth J, Pellacani S, Bradshaw K, Giorgi L. A randomized phase III trial of adjunctive zonisamide in pediatric patients with partial epilepsy. Epilepsia. 2013;54: 1473-80.

87. Guerrini R, Rosati A, Bradshaw K, Giorgi L. Adjunctive zonisamide therapy in the long-term treatment of children with partial epilepsy: results of an open-label extension study of a phase III, randomized, double-blind, placebo-controlled trial. Epilepsia. 2014;55:568-78.

88. Chang XC, Yuan H, Wang Y, Xu HQ, Zheng RY. Eslicarbazepine acetate add-on for drug-resistant partial epilepsy. Cochrane Database Syst Rev. 2011;(12):1-41. Art. No.: CD008907.

89. Almeida L, Minciu I, Nunes T, et al. Pharmacokinetics, efficacy, and tolerability of eslicarbazepine acetate in children and adolescents with epilepsy. J Clin Pharmacol. 2008;48:966-77.

90. Halasz P, Kalviainen R, Mazurkiewicz-Beldzinska M, et al. Adjunctive lacosamide for partial-onset seizures: efficacy and safety results from a randomized controlled trial. Epilepsia. 2009;50:443-53. 
91. Chung S, Sperling MR, Biton V, et al. Lacosamide as adjunctive therapy for partial onset seizures: a randomized controlled trial. Epilepsia. 2010;51(6):958-67.

92. Krauss GL, Serratosa JM, Villanueva V, et al. Randomized phase III study 306: adjunctive perampanel for refractory partial-onset seizures. Neurology. 2012;78:1408-15.

93. French JA, Krauss GL, Biton V, et al. Adjunctive perampanel for refractory partial-onset seizures: randomized phase III study 304. Neurology. 2012;79:589-96.

94. French JA, Krauss GL, Steinhoff BJ, et al. Evaluation of adjunctive perampanel in patients with refractory partial-onset seizures: results of randomized global phase III study 305 . Epilepsia. 2013;54:117-25.

95. Kramer LD, Satlin A, Krauss GL, et al. Perampanel for adjunctive treatment of partial-onset seizures: a pooled doseresponse analysis of phase III studies. Epilepsia. 2014;55: 423-31.

96. Splinter MY. Efficacy of retigabine in adjunctive treatment of partial onset seizures in adults. J Cent Nerv Syst Dis. 2013;5:31-41.

97. Porter RJ, Partiot A, Sachdeo R, Nohria V, Alves WM. Randomized, multicenter, dose-ranging trial of retigabine for partial-onset seizures. Neurology. 2007;68:1197-204.

98. Biton V, Krauss G, Vasquez-Santana B, et al. A randomized, double-blind, placebo-controlled, parallel-group study of rufinamide as adjunctive therapy for refractory partial-onset seizures. Epilepsia. 2011;52:234-42.

99. Glauser T, Kluger G, Sachdeo R, et al. Rufinamide for generalized seizures associated with Lennox-Gastaut syndrome. Neurology. 2008;70:1950-8.

100. Kluger G, Glauser T, Krauss G, et al. Adjunctive rufinamide in Lennox-Gastaut syndrome: a long-term, open-label extension study. Acta Neurol Scand. 2010;122:202-8.

101. Wheless J, Conry J, Krauss G, et al. Safety and tolerability of rufinamide in children with epilepsy: a pooled analysis of 7 clinical studies. J Child Neurol. 2009;24:1520-5.

102. Alsaad AM, Koren G. Exposure to rufinamide and risks of CNS adverse events in drug-resistant epilepsy: a meta-analysis of randomized, placebo-controlled trials. $\mathrm{Br} \mathrm{J}$ Clin Pharmacol. 2014;78:1264-71.

103. Benedict A, Verdian L, Maclaine G. The cost effectiveness of rufinamide in the treatment of Lennox-Gastaut syndrome in the UK. Pharmacoeconomics. 2010;28:185-99.

104. Chiron C, Tonnelier S, Rey E, et al. Stiripentol in childhood partial epilepsy: randomized placebo-controlled trial with enrichment and withdrawal design. J Child Neurol. 2006;21:496-502.

105. Brigo F, Storti M. Stiripentol for focal refractory epilepsy. Cochrane Database Syst Rev 2014;(1):1-21. Art. No.: CD009887.

106. Brigo F, Storti M. Antiepileptic drugs for the treatment of severe myoclonic epilepsy in infancy. Cochrane Database Syst Rev. 2013;(11):1-24. Art. No.: CD010483.

107. Chiron C, Marchand MC, Tran A, et al. Stiripentol in severe myoclonic epilepsy in infancy: a randomised placebo-controlled syndrome-dedicated trial. STICLO Study Group. Lancet. 2000;356:1638-42.

108. Guerrini R, Tonnelier S, dAthis P, et al. Stiripentol in severe myoclonic epilepsy in infancy (SMEI): a placebo-controlled Italian trial. Epilepsia. 2002;43(Suppl 8):155.

109. Gloss D, Vickrey B. Cannabinoids for epilepsy. Cochrane Database Syst Rev. 2014;(3):1-23. Art.No.:CD009270.

110. Guerrini R. Epilepsy in children. Lancet. 2006;367:499-524.

111. Institute of Medicine. Initial National priorities for comparative effectiveness research. Washington, DC: The National Academies Press; 2009.

112. French JA, Gazzola DM. New generation antiepileptic drugs: what do they offer in terms of improved tolerability and safety? Ther Adv Drug Saf. 2011;2:141-58.

113. Patsalos PN, Fröscher W, Pisani F, van Rijn CM. The importance of drug interactions in epilepsy therapy. Epilepsia. 2002;43:365-85.

114. Luszczki JJ. Third-generation antiepileptic drugs: mechanisms of action, pharmacokinetics and interactions. Pharmacol Rep. 2009;61:197-216.

115. Johannessen SI, Landmark CJ. Antiepileptic drug interactionsprinciples and clinical implications. Curr Neuropharmacol. 2010;8:254-67.

116. Guerrini R, Zaccara G, la Marca G, Rosati A. Safety and tolerability of antiepileptic drug treatment in children with epilepsy. Drug Saf. 2012;35:519-33.

117. Wyllie E, Gupta A, Lachhwani DK. The treatment of epilepsy. Principles and practice. 4th ed. Philadelphia: Lippincott, Williams and Wilkins; 2006.

118. Schiemann-Delgado J, Yang H, Loge Cde L, et al. A long-term open-label extension study assessing cognition and behavior, tolerability, safety, and efficacy of adjunctive levetiracetam in children aged 4 to 16 years with partial-onset seizures. J Child Neurol. 2012;27:80-9. 